\title{
DES CONTES
}

\author{
DANIEL GUILLAUME
}

Écrivain

Ma mère me lisait des contes populaires hongrois dans notre maison de banlieue parisienne. Quelques pages, puis c'était à moi d'enchaîner, pour apprendre à lire aussi dans l'autre langue. À nos étés appartenaient plus intimement d'autres séances de lecture, chez mon arrière grand-mère. Elle seule vivait encore (à part ma mère) sur cette branche de la famille. Des motifs ornementaux saturaient le tapis mural et les coussins du canapé-lit, dans l'unique pièce qui lui restait depuis la guerre, à l'angle de sa propre villa de Buda, bombardée par les alliés, reconstruite par d'autres puis redistribuée par l'État. Elle n'y chauffait ni les toilettes ni la cuisine, et se lavait à la bassine, d'émail blanc liséré de bleu, dans cette chambre-salon. Ces fleurs étranges, ces formes géométriques et suggestions d'animaux, condensaient en quelque sorte leurs équivalents fortunés du grand salon, chez la famille adoptive, où sur le parquet vide s'étendait un gigantesque tapis persan à base losangée sur un fond dominant nuit, d'après le souvenir que je garde de ce sol vaste mais peu pratique, à cause des plissements de la trame pelucheuse, élimée ou rêche, pour y déploye le petit train électrique ou y dresser mes plus ambitieuses constructions de bois : cylindres, cubes et parallélépipèdes s'ajointaient et tenaient mal, sur cette épaisseur. Ces tissus ont pu me convaincre qu'en terme d'humanité il n'y a pas d'atome, au fond. Pas de limite à l'analyse. Notre matière est absolument historiée. Et cette aïeule, mon arrière grand-mère née en 1887 dans son petit bourg d'une région que les accords de Trianon firent croate, sa voix contenait celle de ma mère, pour qui elle avait dû raconter de même. Mais à feuilleter de nouveau ces livres de mon enfance, j'entends aussi la voix des conteurs salariés par la radio de la Démocratie populaire, à l'époque, pour continuer de faire vivre cette parole astucieuse et enchanteresse des villages, malgré la botte du Grand frère, malgré la patte de l'ours soviétique. Ce timbre de l'aïeule remontait pour moi jusqu'à une chronique orale des Habsbourg. Non tant par les faits - largement opaques, à leur source, puisque jusqu'au bout la vieille dame, presque centenaire, a cru que je ne la savais pas juive - que par des préjugés. Une certaine façon de voir les choses. Le quotidien de l'Histoire. Avec l'Empire, elle avait en- 
trevu ce siècle, le dix-neuvième, qui dans mon esprit se rattache encore au royaume des contes.

J'en ai bien sûr connu des versions destinées aux gens des villes, comme chez Perrault, Grimm, ou Fabre d'Eglantine. « Il pleut, il pleut, bergère... » vient bien d'un opéra comique. Avec les années et les déménagements, j'ai perdu et largement oublié ces récits, adaptés par Elek Benedek ou Gyula Illyés. Il m’en reste pour l'essentiel une seule intrigue, bien connue, qui ne pouvait que me toucher : un cadet de trois frères terrasse le dragon, il comble ainsi de joie le vieux roi et conquiert la princesse (de mes deux demi-frères aînés, je n'en connaissais pourtant qu'un seul). Mais plus encore que des histoires, ces contes m'ont laissé des tournures, des motifs. Le dragon à sept têtes (hétfejü sárkány). La formule initiale - mot à mot : « Où c'était, où ce n'était pas » (hol volt, hol nem volt) : elle ouvre la frontière des possibles, en suggérant qu'une même chose peut à la fois être et ne pas être. La jeune fille détenue par un monstre, un sorcier ou un roi félon, se trouvait toujours dans la plus haute tour d'un palais merveilleux « tournant sur une patte de canard » (kacsa lábon forgó palota). Ce'qui m'évoque tout de suite un bouillon de poule. Soit que je veuille ainsi, d'emblée, coudre qu-à Paris d'Henri IV, avec sa poule au pot, car Pau est à la fois, si je puis dire, la ville d'enfance de ce bon Bourbon, avec son berceau en carapace de tortue, et celle de mon père - autre « vert galant », d'ailleurs. Soit que, le passé rural restant bien plus vivant, dans la Hongrie des années 1970, même en ville, qu'à Paris, on y déjeunât, tout simplement, plus volontiers de soupe où l'on peut jeter une patte de poule. À moins que cette expression pour dire une splendeur impossible renvoie carrément à l'oiseau totémique du Kalevala finlandais ? Dans cette épopée, en effet, le canard envoyé par un Dieu fainéant plonge dans le limon pour en ressortir avec dans le bec de quoi faire le premier homme. Mais la separation finno-ougrienne remonte quand même à loin, du côté de l'Oural. Et en Hongrie, les éléments nordiques restent rares, ténus. Réduits à quelques mots : « poisson », par exemple, se dit hal - kala, en finnois. Ils sont culturellement, bien plus marginaux que les traits scythes. Par exemple, feindre la fuite à cheval, puis se retourner soudain pour décocher une pluie de flèches, caractérisa aussi les cavaliers magyars. On décèle chez ces derniers plus de familiarité encore avec les peuples turcs, dont la brouillonne confédération hunnique fut conduite un temps jusqu'en France par Attila. Ses troupes redoutables se signalaient par le port de la natte, un certain type de chaudron pour faire cuire les victimes propitiatoires, ou encore une structure des clans familiaux que l'on retrouve autour des sept chefs qui occupèrent, au sortir de la steppe, le morceau de bassin carpatique nommé, plus tard, Hongrie. « Où c'était, où ce n'était pas ", le dragon à sept têtes et les palais tournant sur patte de canard furent en tout cas mes « paroles ailées », mon « aurore aux doigts de rose ». Rien à faire : les contes en français me sont toujours apparus un peu fades, édulcorés, par rapport aux hongrois qui constituent je crois la matière première, pour moi, lointaine et proche, intime comme l'oubli, de toute littérature. Très attachées à ce fol- 
klore, ma mère et mon arrière grand-mère juives faisaient de leurs voix, par ces récits, comme un lit profond, tout de draps frais et couvette en plume, à cette grand-mère (fille de celle-à, mère de celle-là) que les Croix fléchées conduisirent à la mort. Ces deux femmes recouvraient ainsi le massacre, et intégraient tout un passé - oriental ? - dont je ne sais rien, à part quelques prénoms sur de vieux papiers (Moïse, Jacob), dans des arbres généalogiques reconstitués à la hâte, au crayon de plomb face aux lois raciales, et à part une certaine prédilection, chez elles, toutes deux chrétiennes de religion, pour l'Ancien testament. Elles m'ont convaincu que la lecture (et donc l'écriture qui la rend possible) faisait arriver à bon port. Vif, gratuit, apparemment coupé des affaires sérieuses - adultes - (à moins qu'il n'en soit secrètement la patte de canard: le pied d'argile ?), ce plaisir travaille le nœud de l'Histoire. Il vibrait dans les mots et leurs timbres, dans les intonations douces et profondes des mères.

Petófi tente hardiment ce lien des mondes, dans un conte en vers où il orchestre avec astuce des éléments populaires. Parmi les exploits de son personnage Jean le Preux (János vitéz), il n'y a rien moins, en effet, que de sauver le roi de France face à l'invasion des Turcs. János traverse pour cela les Alpes à cheval, sur les traces des légions romaines. Mais il refusera la main de la princesse atlantique, par amour de sa bergère Juliska. Elle est restée l'attendre au village. Il ne sait pas encore qu'elle est morte. Sans trop d'illusion sans doute, avant 1848 (Petőfi mourra dans l'insurrection), la Hongrie romantique soulevée contre les Habsbourg se rêvait salvatrice de l'Occident. Vieille histoire. Les chevaliers de mes rêves purent donc sans gêne être binationaux. Historiquement, toutefois, de François premier et Louis quatorze à la Petite Entente, les alliances gauloises vont plutôt vers l'orient : jusqu'à Constantinople, vers la Pologne et la Serbie pour prendre à revers les Habsbourg. Ce Prince hongrois, François II Rákóczi de Transylvanie, en connut la désillusion. L'occupation autrichienne devenant pire que la turque, et la Pologne de Sobieski faisant faux-bond, les Malcontents hongrois, regroupés derrière Rákóczi, servirent un moment Louis XIV pour coincer en tenaille Léopold et l'Empire, pendant la guerre de succession d'Espagne. Derrière son étendard, brandi parfois malgré lui, les serfs partis se battre avec faux et cognées, les haïdouks et autres partisans ont poussé leurs troupes en désordre jusqu'à Vienne. Mais les choses se gâtèrent assez vite, par l'ouest. La France fatigue, dans ses petits jeux d'alliances. Son peuple s'épuise, ponctionné par les fermiers généraux. La crise couve dès avant le Grand hiver, quand la Seine gela depuis Paris jusqu'à son embouchure. À partir d'Höchstadt, les batailles perdues succédèrent donc pour Rákóczi aux succès de la guérilla. On refusait sa monnaie de cuivre et, à force aussi de libertés promises par leur chef héroïque, naïf, obstiné, aux loqueteux qui font le gros des troupes mais qui ne rapportent plus, les chefs de son armée, les grands, pensent de plus en plus à récupérer leurs privilèges. Quitte à en rabattre, sur l'indépendance. Versailles paye moins. Négocie. Le Tsar les balade. 
Sa cause est de toute évidence perdue, mais le Prince refuse. Que d'autres signent des traités conciliants. Lui s'exile. À la cour de France, sa femme, dont les désordres contribuèrent à le jeter dans une pratique austère, elle, favorite de Madame de Maintenon, l'introduisit dans la meilleure société. Il voyait le roi librement, sans ostentation. Il rédigeait ses Mémoires en français et fut de toutes les chasses, de tous les voyages à Marly. La rigueur d'un quotidien très strict (au pain sec et à l'eau, une ou deux fois la semaine) et ses retraites, même, à l'abbaye de Grosbois, n'empêchaient pas qu'il possédât, sur le Quai Malaquais, cet Hôtel de Transylvanie où vous vous rappelez peut-être que Lescaut, le frère de Manon, ayant introduit le Chevalier des Grieux dans sa ligue de l'industrie, lui apprend à tricher au jeu : c'était avec les officiers d'un certain Prince de R. D'Argenson, lieutenant de police, n'avait peut-être pas tort de s'inquiéter des désordres que pouvait créer un tel établissement. Pourtant, malgré ce qu'en avait toujours dit ma mère, il ne s'agissait pas d'un bordel. Je pus le vérifier à la Sorbonne. Je feuilletai quelques Pléiades sous les plafonds à bords bleus pâles, avec leurs discutables fresques Second Empire. Richelieu, François $1^{\mathrm{er}}$. Tout diplôme passé, je peinais à rester, comme dans tout lieu de travail public, d'ailleurs, parmi ces étudiants plus jeunes, ces enseignants et ces chercheurs, dans un univers où dans mon genre n'avait guère sa place. Il traverse donc la bibliothèque et s'éclipse, voyeur entré par effraction - à moins que ce ne soit avec l'accord, cette fois, d'occupants titrés que ça excite : ils relèvent leur chemise de nuit, turgescents et grognant, lâchent leurs mains sur les chairs - dans la chambre à coucher derrière les rideaux pourpres de laquelle une pervers mortifié se cache. Saint-Simon écrit de Rákóczi qu'il avait un air tartare. " Fort honnête homme» mais «de fort peu d'esprit ». Son secrétaire, Kelemen, raconte la vie très réglée du dernier exil, lorsque ce maître finit par répondre à l'invitation du Sultan : le lever à cinq heures et les multiples messes, les prières quotidiennes au battement du tambour. Revenu de ses débuts frivoles, viennois, de tout son passé politique et mondain, Rákóczi a terminé là ses Confessions, prenant modèle sur Saint Augustin. En latin donc, cette fois, sur les bords de la mer de Marmara, dans une maison qu'on se figure entourée de roses. Il souffrait de la goutte. Quand il mourut, le sang dans son corps semblait s'être changé en une boue argileuse. On se plaît tout de même à imaginer pour un tel homme une fin plus Régence. D'agréables retours de jeunesse. Les janissaires à sa porte et la rigueur spirituelle n'empêchèrent peut-être pas qu'on l'aère de palmes, qu'on le parfume de pénétrantes senteurs. De jolies esclaves se font alors prendre par lui dans des poses. Distensio animi. Elles répondent à ses gestes un peu las par des initiatives intelligentes : mots piquants et flatteries de couilles, doigts fins et longues langues, sur les coussins d'une salle subtilement protégée de la chaleur environnante, qui vibre. 